\title{
Imigrantes japoneses em Marco zero e Amar, verbo intransitivo
}

\section{Roberto Akira Goto ${ }^{1}$}

\section{Resumo}

Este artigo analisa as imagens que Marco zero, de Oswald de Andrade, e Amar, verbo intransitivo, de Mário de Andrade, projetam dos imigrantes japoneses, contra o pano de fundo de suas relações com o povo brasileiro. Tal análise leva em conta a caracterização dos personagens nipônicos pelos romancistas, sobretudo no que diz respeito às suas individualidades.

\section{Palavras-chave}

Japoneses, brasileiros, imigrantes

Recebido em 11 de abril de 2012

Aprovado em 6 de julho de 2012

GOTO, Roberto. Imigrantes japoneses em Marco zero e Amar, verbo intransitivo. Revista IEB, São Paulo, ก. 55, p. $149-164,2012$.

1 Professor doutor do Departamento de Filosofia e História da Educação da Faculdade de Educação da Universidade Estadual de Campinas (Unicamp, Campinas, SP, Brasil).E-mail: goto@unicamp.br 


\section{Japanese immigrants in Marco zero and Amar, verbo intransitivo}

\section{Roberto Akira Goto}

\section{Abstract}

This paper analyzes the Japanese immigrants' images that Oswald de Andrade's Marco zero and Mário de Andrade's Amar, verbo intransitivo project, against the background of their relations to the Brazilian people. This analysis takes into consideration the making-up of the Nipponese characters by the novelists, over all concerning their individualities.

Keywords

Japanese men, Brazilian men, immigrants 


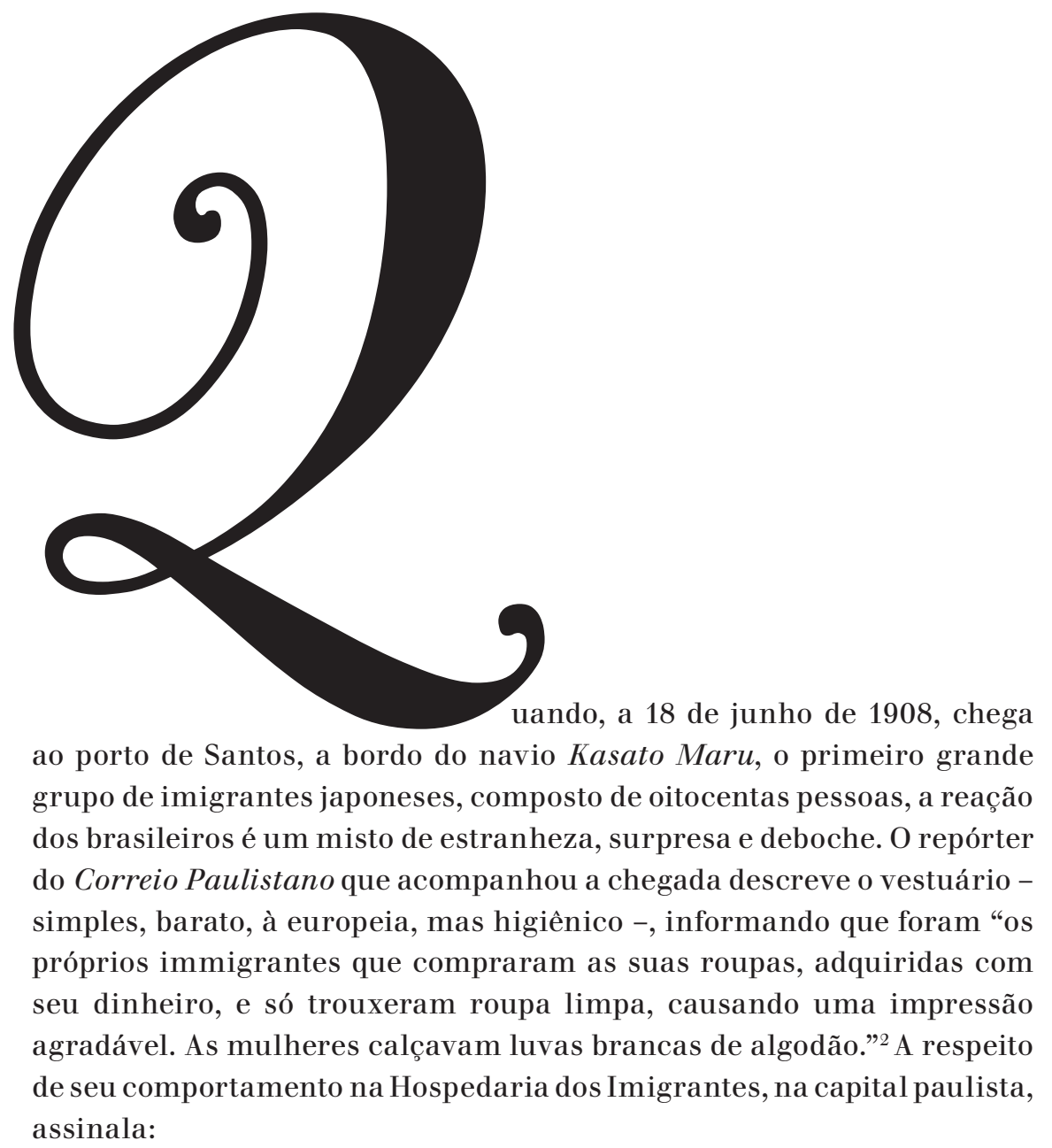

Depois de estarem uma hora no refeitório, tiveram de abandonal-o, para saberem quaes eram as suas camas e os quartos, e surprehendeu a todos o estado de limpeza absoluta em que ficou o salão: nem uma ponta de cigarro, nem um cuspo, perfeito contraste com as cuspinheiras repugnantes e pontas de cigarro esmagadas com os pés dos outros immigrantes. ${ }^{3}$

Mais de uma vez o jornalista (a)nota essa ordem asseada, caracterizando os imigrantes nipônicos como

2 Apud HANDA, Tomoo. Memórias de um imigrante japonês no Brasil. São Paulo: T. A. Queiroz, 1980, p. 6.

3 Idem, p. 7 . 
muito doceis e sociaveis, tendo manifestado uma grande vontade de aprender a nossa lingua, e no refeitorio não deixam cahir um grão de arroz ou uma colher de caldo. Depois de cada refeição (que dura de uma e meia a duas horas), o pavimento do salão está como antes della. Os dormitorios quasi não precisam ser varridos, mal se encontrando de longe em longe um pedacinho de papel ou um phosphoro queimado, que algumas vezes são dos serventes da hospedaria.

$[\ldots]$

São do maior asseio com o seu corpo, tomando repetidos banhos e trazendo sempre roupas limpas.

$[\ldots]$

Todos têm uma caixa de pós dentifricios, escova para dentes, raspadeira para a lingua, pente para o cabello e navalha de barba. Barbeiam-se sem sabão, só com água. ${ }^{4}$

Fisicamente, os japoneses são descritos pelo repórter como

geralmente baixos: cabeça grande, troncos grandes e reforçados, mas pernas curtas. Um japonez de 14 annos não é mais alto que uma criança das nossas de 8 annos de edade. A estatura média japoneza é inferior à nossa estatura baixa. Mas vieram alguns homens altos, regulando a sua estatura pela nossa média. O que, sobretudo, attráe a nossa attenção é a robustez, o reforçado dos corpos masculinos, de musculos pouco volumosos (admira, mas é verdade!) mas fortes e de esqueleto largo, peito amplo. ${ }^{5}$

Quanto à inserção dessa mão de obra na economia nacional, o jornalista arrisca a hipótese de que "a riqueza paulista terá no japonez um elemento de produção que nada deixará a desejar", ressalvando: "A raça é muito differente, mas não é inferior. Não façamos, antes do tempo, juízos temerários a respeito da acção do japonez no trabalho nacional” ${ }^{\text {. }}$

Outros que não o polido e cauteloso repórter reagiram com menos tato. Os faxineiros da Hospedaria, por exemplo, divertiram-se ensinando palavrões às moças japonesas que queriam saber como se chamavam em português coisas como olhos e nariz e que anotavam cândida e diligentemente as respostas:

\footnotetext{
4. Idem, p. 9-10.

5 Idem, p. 8.

6 Idem, p. 10.
} 
Sucedeu que chegou a ocasião de fazerem diante do diretor Fraga a demonstração do português aprendido havia pouco. A cada palavra expressa pelas moças seu rosto corava de ira; ao ouvir a palavra final [...] seu corpo foi sacudido por um arrepio. Mesmo assim, limitou-se a dizer-lhes: "Está bom". Só que, em seguida, sem perda de tempo entrou em ação, chamando Herculano, o encarregado da faxina, ordenando-lhe que reunisse no refeitório todos os empregados. E aí, em tom veemente, declarou que "iria despedir, energicamente, quem de futuro se atrevesse a ensinar palavrões às moças japonesas". ${ }^{7}$

Não foi diferente a recepção aos que se aventuraram a sair à rua, o que se deu às 13 horas do sexto dia de estada na Hospedaria: alguns "gaiatos 'punham-se à frente dos japoneses e, a encararem o nariz chato, apertavam os seus narizes enormes com os dedos ${ }^{8}$ ". Em vista desse tipo de reação, não há certeza quanto ao lugar exato do passeio:

No Largo da Sé as mulheres e crianças foram cercadas por uma multidão de curiosos. "Por duas horas, elas nem puderam prosseguir a caminhada. Parece mentira, mas é a pura verdade" - assim relata a História dos 40 anos. Todavia, não é possível comprovar que esse fato houvesse ocorrido no Largo da Sé. De acordo com o registrado em Os pioneiros da imigração (p. 388), se, de um lado, realmente cinco intérpretes homens conduziram contrafeitos as imigrantes, e isso porque foi ordem do diretor ("Levem-nas a uma visita à cidade"), por outro lado conta-se entre alguns relatos jocosos que: "Vendo-se seguidos por um grupo de mulheres, com vestidos pretos que lembravam a luto e chapéus de palha chatos ornados de flores vermelhas, a caminhar a passos curtos de mulheres de ópera a quem chamam de gueixas, os intérpretes, embaraçados ao extremo, se limitaram a dar uma volta pelo bairro do Brás, dizendo que estavam a ver a cidade de São Paulo. Nenhum deles chegou a atingir o centro formado pelo triângulo." ${ }^{9}$

7 Idem, p. 12. O autor cita SUZUKI, Teijiro. Os pioneiros da imigração japonesa no Brasil.

8 Idem, p. 12. Handa cita KOUYAMA, Rocro. História dos 40 anos da imigração japonesa.

$9 \quad$ Idem, p. 13. 
Os escritores modernistas, atentos à realidade brasileira e às suas transformações, preocupados em sincronizar a história do país com os apelos das vanguardas estéticas que proliferavam na Europa, ao mesmo tempo que, imbuídos de um impulso nacionalista, não permaneceram indiferentes ao processo de imigração, inclusive daqueles que eram (são?) encarados como exóticos e estranhos. Mas, por conta de suas próprias ambivalências, as imagens que compuseram dos imigrantes nipônicos não poderiam deixar de ser, elas também, ambíguas e problemáticas, nem sempre tão "modernas" e vanguardistas quanto as formas estéticas empregadas. Talvez isso as torne mais interessantes, ou pelo menos dignas de análise e discussão.

\section{Marco zero}

Os imigrantes japoneses constituem presença numerosa em Marco zero, de Oswald de Andrade. Composta de dois romances - A revolução melancólica e Chão -, a obra foi iniciada, segundo o autor, em 1933; o primeiro volume concluiu-se em 1942 e o segundo em 1944. O escritor define Marco zero como uma "tentativa de romance mural" que "tende ao afresco social". Para ele, o gênero romanesco "participa da pintura, do cinema e do debate público" e "mais que da música que é silêncio, é recolhimento"10.

A galeria dos personagens nipônicos inclui: a) Muraoka, comerciante e proprietário de terras; b) "Nhô Fusiko", uma espécie de capataz; c) as crianças que frequentam o Grupo Escolar de Bartira (Kioto Nassura, Sakueto Sakuragi, Massao Moraoka etc.); d) Kana, motorista e piloto do conde Alberto de Melo; e) o bonzo de Porto Litoral; f) a mulher casada que diz ao Padre Beato que precisa ter doze filhos porque "Governo japuneis manda... munto perecisa"11; g) Dr. Sakura, engenheiro que fixa os colonos trazidos pela Companhia de Imigração; h) os habitantes da cidade de Registro - "Registro-Gô, a capital amarela do Sul"12; i) a criadinha do deputado Pádua Lopes.

Classificá-los como personagens, no sentido mais estrito do termo, talvez seja um pouco abusivo. A maioria deles está mais próximo do

10 Cf. ANDRADE, Oswald de. A revolução melancólica. Rio de Janeiro: Civilização Brasileira, 1974, p. 280.

11 Idem, p. 109.

12 Idem, p. 112: "Sobre a barranca saneada", prossegue o narrador, "os japoneses haviam erguido hangares e chaminés e dali se irradiavam estrategicamente por estradas de cem léguas”. 
estatuto de figurantes, frequentemente não sendo mais que objeto de uma enumeração pitoresca ou de uma citação passageira. Muito raramente o autor lhes confere a palavra para que exprimam seu caráter próprio, para que seu $e u$ se manifeste. No mais das vezes, são caracterizados de fora, olhados e julgados pela visão do outro - seja ele um personagem, seja o próprio narrador.

Mais exato seria dizer que em Marco zero os imigrantes japoneses formam um personagem coletivo, resultante da fusão - e da desconsideração - das características individuais num grande clichê: são os "amarelos", os "dissimulados", os "indiferentes", aqueles de cuja alma se pode "esperar tudo" ${ }^{13}$, gente "impassível" que vinha espiar, invadir e ocupar o Brasil, a serviço do Império do Sol Nascente, do imperialismo nipônico.

O perigo da ocupação do território brasileiro pelos japoneses é um dos motivos condutores da obra, podendo ser ouvido tanto no discurso indireto livre do narrador quanto nas vozes de personagens como o comunista Leonardo Mesa e o mulato Lírio Rebouças do Vale Piratininga. "Espiões educados, outros transformados em pescadores ou em peritos de agricultura, penetravam nos escritórios e nas casas, levantavam mapas do litoral e do interior"14, pensa o primeiro, de codinome Rioja, que ao entrar no Brasil vê a alfândega deixar passar para a cidade de Registro "até aeroplanos desmontados e metralhadoras, como máquinas agrícolas" ${ }^{\prime \prime}$.

Já o farmacêutico Lírio Piratininga escreve para a Voz de Jurema, jornal da cidade homônima:

No criado, no chofer, no lavrador, no jardineiro, no comerciante, no pescador ou no burocrata... ou no milionário, enfim em qualquer ramo em que se desenvolva sua aparente atividade, está o técnico, o militar, o sociólogo, o polígrafo, o informante e o repórter a estudar, a inquirir, a observar e a transmitir memórias, relatórios e estatísticas para a sede desse formidável quartel-general que, em Tóquio, prepara a maior guerra de conquista de que a história humana jamais teve ideia. ${ }^{16}$

13 Idem, p. 67. A cena é a do conde Alberto de Melo enfrentando uma turbulência no avião pilotado por Kana.

14 Idem, p. 18.

15 Idem, p. 16.

16 Idem, p. 7 . 
Por seu turno, a voz do japonês, quando soa, não produz um efeito de individualização. Ouçamos, por exemplo, o Dr. Sakura tentando explicar os motivos da imigração de seus compatriotas:

Munto pobereza. Governo non dá saída de produção em mercado interno. [...] Outro paíse melhor situação pobereza. Depois perecisa imigrá pra Burasil. Todas nação proíbe entrada de produto japoneis. Disque é dumping, mas não é porque pobereza perecisa de comê, vende maise borato. Armamento também governo munto gasta. Mais de vinte por cento de renda nacional. ${ }^{17}$

A reprodução da fala do imigrante, ao contrário do que se poderia esperar, não individualiza o falante. Na medida em que tal fala remete ao coletivo, por meio dos clichês da prosódia atribuída ao grupo, o máximo efeito que consegue é o do pitoresco, acabando por puxar o indivíduo para o tipo, o estereótipo.

No contexto do romance, as vozes nipônicas são um contraponto tímido ao leitmotiv da ocupação imperialista do Brasil pelos japoneses, mesmo quando (como no caso do Dr. Sakura) procuram dizer o contrário. A versão de que o imigrante é um espião-invasor acaba prevalecendo, à esquerda e à direita: a adesão de Kana à Revolução de 1932 (a melancólica do título) e, posteriormente (em Chão), aos integralistas ${ }^{18}$, não lhe retira o caráter enigmático, exótico, sempre pouco digno de confiança.

Esse tipo de contraste não ganha relevo na obra. Na verdade, mal aparece: o fato de Kana, o japonês educado na Inglaterra, formar fileira com os revolucionários paulistas e colaborar com os ultranacionalistas liderados por Plínio Salgado, não contradiz o diagnóstico do expansionismo nipônico; trata-se da exceção que confirma a regra. Por outro lado, se o autor de Marco zero parece às vezes mostrar simpatia pelo movimento de $32 \mathrm{ou}$, no mínimo, não esconde sua antipatia contra a ditadura getulista, ao mesmo tempo não deixa de incorporar a ideia que essa ditadura fazia do imigrante japonês: "O Grupo Escolar havia sido salão de baile nos tempos idos, quando o imigrante japonês invadira o litoral sul do Estado, encaminhando-se para a formação de seus quistos raciais." ${ }^{9}$

Dada tal combinação do enigmático com o estereotipado, pouco ou nada se deve esperar quanto à representação da vida psicológica dos

\footnotetext{
17 Idem, p. 109.

18 Cf. ANDRADE, Oswald de. Chão. Rio de Janeiro: Civilização Brasileira, 1974, p. 228-229.

19 Idem, A revolução melancólica, p. 40.
} 
personagens japoneses. No caso de outros, como caipiras e italianos, o estereótipo não chega a ser um obstáculo para que o autor franqueie ao leitor o psiquismo dos personagens. O mesmo não acontece com os japoneses: estes aparecem como literalmente - literariamente - indevassáveis, e o fato de não se manifestar sua interioridade confirma e reforça seu caráter enigmático, estranho, exótico - algo que continuará fazendo fortuna na Literatura Brasileira.

Figuras planas, bidimensionais (ou mesmo unidimensionais), os japoneses de Marco zero ganham do escritor um retrato que beira, quase sempre, o caricatural. Essa falta de profundidade não combina com a concepção de um romance mural caracterizado pela trama complexa das imagens e dos pontos de vista. Na díade oswaldiana, a complexidade é sacrificada à ideologia da Antropofagia, que o escritor parece adotar como princípio de composição e montagem de seu mural (e que é mais de uma vez citada e debatida em $C h \tilde{a} o^{20}$ ).

O muralismo que Oswald de Andrade toma por modelo não é o dos painéis épicos, mas o das pinturas de tons carregados, de caracteres altamente ideologizados: atravessados por olhares de Medusa, os dois romances acabam por exibir personagens petrificados, figuras que representam antes de mais nada a cristalização de um princípio ideológico. Como se obrigando a demonstrar a existência de relações antropofágicas - ou, melhor dizendo, antropófagas - no processo social, Oswald de Andrade exacerba e escancara as tensões sociais e raciais: os grupos figurados aparecem, uns aos olhos dos outros, sob as luzes e os ângulos mais desfavoráveis. À polifonia dos murais épicos, o autor prefere as dissonâncias da maledicência: em Marco zero, todos - incluindo o narrador - falam e pensam mal de todos. A obra soa folhetinesca, bombástica, circense.

Essa música de picadeiro, que - a despeito da classificação do autor - está longe de ser intimista e de produzir o senso de recolhimento, certamente paga tributo à época que o escritor quis retratar e àquela em que escreveu sua obra, mas parece dever muito mais à sua opção de estilo, em que observações acres e impiedosas mesclam-se com clichês

20 Palavras que o autor põe na boca do personagem Jack São Cristóvão: “No meio do movimento modernista apareceu alguma coisa tão rica e fecunda que até hoje admite várias interpretações. Politicamente, a Antropofagia pode ser considerada como a primeira reação consciente contra os imperialismos que ameaçam até hoje a nossa independência. [...] As origens intelectuais da Antropofagia estão em Montaigne, em Rousseau. É a exaltação do homem natural, com uma diferença, não o elogio do 'bom selvagem', mas do mau, do verdadeiro...” Cf. Chão, p. 202. Mais adiante (p. 231), a Antropofagia é mencionada numa conferência sobre tempo e música. 
melodramáticos ${ }^{21}$, tudo envolvido por uma atmosfera de decadência e caos. É a música da Antropofagia, cujo refrão martela: "a vida é devoração; devorai-vos uns aos outros".

\section{Amar, verbo intransitivo}

Em Amar, verbo intransitivo, de Mário de Andrade, a imagem do imigrante japonês se desenha (ou se esboça) em contraste com a imagem da imigrante alemã, a Fräulein. Motivo ou pretexto do contraponto é um poema de Castro Alves, "A queimada", que exclama em sua sexta estrofe:

A queimada! A queimada é uma fornalha!

A irara - pula; o cascavel - chocalha...

Raiva, espuma o tapir!

...E às vezes sobre o cume de um rochedo

A corça e o tigre - náufragos do medo -

Vão trêmulos se unir!?2

A catástrofe natural descrita pelo poeta romântico ganha, nas mãos do escritor modernista, o sentido de metáfora da situação históricopolítica que conduz uma alemã e um japonês a se encontrarem, ao mesmo tempo unidos e distanciados, na condição de criados da família Sousa Costa. Entretanto, o romancista reformula a metáfora para adequá-la à realidade, lembrando que nem a alemã nem o japonês poderiam ser representados por uma corça: ambos são tigres - rivalizam no poder e na impotência, no orgulho e no desamparo.

O distanciamento a que obrigam o uso da metáfora e o estilo do narrador - que intervém a todo instante com comentários e observações - é o que permite, paradoxalmente, uma aproximação maior da situação do imigrante, quase tocando em sua interioridade. Observemos e acompanhemos esse movimento na narrativa:

Falemos dos tigres. O japonês arrepiou logo o pelame elétrico e grunhiu zangadíssimo. Mais uma estrangeira na casa que ele pretendia conquistar, ele só... O tigre alemão, se reconhecendo

21 Um exemplo entre muitos: em A revolução melancólica (p. 148), Eufrásia diz a Jango: "Toquei pela primeira vez a realidade, a realidade maravilhosa que você é. Agora sei o que é essa coisa insondável, o amor..."

22 Cf. ALVES, Castro. "A queimada", poema do livro A cachoeira de Paulo Afonso, lido na antologia Canto da esperança. Rio de Janeiro: Nova Fronteira, 1990. 
muito superior tanto na hierarquia solarenga como na instrução ocidental, lhe secundou ao grunhido com o muxoxo desdenhoso. $\mathrm{O}$ tigre japonês curvou a cabeça, muito servilmente. [...] Era na alma que rosnava tiririca. E assim os dois tigres se odiavam. Viviam se arranhando em contínua rivalidade. Cada um se acreditava o dono daquela família, o conquistador da casa e do jardim, o quem sabe? futuro possuidor do Estado e próximo rei da terra brasileira toda do Amazonas ao Prata.

[...] De repente os cipós se entreabriam. Dois olhos espantados relampeavam na escureza e a carantonha chata do tigre japonês aparecia, glabra, polida pelo reflexo lunar. Com o passo enluvado, cauteloso, ele rondava à espera dum carinho. E o carinho chegava fatalmente. [...]

[...] Então eles conversavam. Falavam longamente. Comovidamente. Se contavam as mágoas passadas. Confiantes, solitários. Doloridos. [...] As infâncias passavam lindas, inocentes, brinquedos, primavera, mamãe... Algumas vezes mesmo uma lágrima iluminava tanta recordação, tanta alegria. Tanta infelicidade.

[...]

Depois das recordações, vinham as esperanças. E das esperanças, tão lentas de se realizar! derivavam os exasperos e as revoltas. Até calúnias, tão eficientes pra consolar. A roupa suja da família se quotidianizava ali. Os defeitos da pátria emprestada eram repassados com exagero. Principalmente o nipônico falava, que o alemão tinha as pernas mais altas do estudo pra se rojar no lamedo. Porém se percebia que escutava com prazer. E os dois tigres se aproximavam, olhos úmidos, eram irmãos. Si a distância lhes impedia pra sempre o beijo sem desejo, insexual mas físico de irmãos, eles se davam, não tem dúvida, aquele beijo consolador, espiritual, redentor e reunidor das almas desinfelizes e exiladas.

Apalermados pela miséria, batidos pelo mesmo anseio de salvação, sofrenados pelo fogaréu do egoísmo e da inveja, na mesma rocha vão trêmulos se unir. A queimada esbraveja em torno. ${ }^{23}$

Por outro lado, a metáfora não provê a individualização. O “tigre” Tanaka é ainda, e sobretudo, um representante do império nipônico, sua individualidade é subsumida em sua condição de japonês - em sua, digamos, "japonidade". "O tigre japonês, chato, contorcido, ver um

23 Cf. ANDRADE, Mário de. Amar, verbo intransitivo. São Paulo: Livraria Martins Editora, 1972, p. 93-95. 
Chuntai" "24. A menção das características físico-biológicas está aí não só para fazer lembrar que o indivíduo integra e representa uma etnia, mas também para indicar que a essa etnia correspondem uma cultura e uma sociedade, as quais o indivíduo encarna e, igualmente, representa. O natural é, também, nesse sentido, sinal do cultural.

Além disso, o que interessa ao autor e a seu narrador é discutir o destino e o futuro desses imigrantes como coletividades, não propriamente como indivíduos: ele quer saber se, como e quando esses grupos se integrariam à vida brasileira, sobretudo à nacionalidade brasileira. Nesse ponto, embora escreva bem uns seis anos antes de Oswald de Andrade (o "idílio" é de 1927), Mário de Andrade parece dispor de uma percepção ou intuição mais aguda e sensata: “Os dois tigres acabarão por desaparecer assimilados"25.

Mário de Andrade também acerta, parcialmente, ao ponderar sobre o perigo que ronda a aculturação dos imigrantes. Segundo o narrador, o risco ou o obstáculo não reside nas crenças milenares de cada povo (e que se referem, talvez, às camadas culturais mais profundas), mas nas ideias e na ação de doutrinadores ou ideólogos como Gobineau:

Homem, não sei. Avisto Gobineau fraudulento a estudar o facies de Tupã. Odin e Budá inda Tupã podia vencer, que em brigas entre iguais a vitória parece discutível. Mas Gobineau é homem, Homo Europeus, e sempre constatei que os homens são muito mais fortes que os deuses. Gobineau vencerá pra maior gozo de alemães. ${ }^{26}$

24 Idem, p. 95 .

25 Idem, p. 96.

26 Idem, ibidem. O narrador refere-se ao francês Joseph Arthur de Gobineau (18161882), que em 1853 se fez conde e escreveu o Ensaio sobre a desigualdade das raças humanas, no qual defende a superioridade da raça ariana. De abril de 1869 a maio de 1870 , o conde de Gobineau foi ministro (embaixador) da França junto à corte de D. Pedro II, tornando-se amigo do imperador brasileiro. De volta ao país natal, chegou a cogitar escrever uma "novela brasileira", o que lhe pareceu "impossível", de um lado porque os brasileiros "não despertam nenhum interesse e não têm nem costumes nacionais nem nada de particular, a não ser uma excessiva depravação com o qual se pode fazer um livro muito severo e muito duro, mas não uma novela"; de outro, porque "gosto demais do Imperador para escrever uma só palavra contra este povo infame. Todos mulatos, a ralé do gênero humano, e costumes condizentes. Estão pervertidos pela escravidão dos negros, e os negros pervertidos por..." (cf. RAEDERS, Georges. O inimigo cordial do Brasil: o conde de Gobineau no Brasil. Trad. Rosa Freire d'Aguiar. Rio de Janeiro: Paz e Terra, 1988, p. 181-182). 


\section{O enigma e suas variações}

Uma comparação entre as obras dos dois modernistas indicará provavelmente que o retrato do Tanaka de Amar, verbo intransitivo é mais humano e mais razoável que as várias pinturas que Oswald de Andrade faz dos japoneses em seu romance mural, justamente porque menos pitoresco (ou pinturesco), menos caricatural. Por outro lado, o "idílio" e Marco Zero assemelham-se ao observarem e anotarem os tremores do chão e do subsolo sociais: a aversão de brasileiros aos nipônicos e a outros estrangeiros; a hostilidade ou rivalidade entre estes últimos - enfim, tensões que ganharam da parte de Oswald de Andrade a representação mais exacerbada.

Como já se notou, Mário de Andrade avança na busca da interioridade do personagem japonês, mas não se pode dizer que tenha alcançado a sua individualidade, a exemplo do que também ocorre - e de forma mais acentuada - na obra de Oswald de Andrade. Na Literatura Brasileira, a aura mais negativa que positiva do enigmático, do estranho, do exótico, permanece como uma espécie de legado que o imigrante nipônico acumula e transfere aos descendentes. Vinte anos após Marco zero ainda se verá um João Antônio, com o conto "Fujie", traçar da moça de origem nipônica a imagem da mulher-enigma, da esfinge cujos mistérios nem a mais estreita intimidade desvenda: imagem fugidia, que se projeta em negativo, “definindo-se” pela ausência de definição, pelo obscuro ${ }^{27}$.

Comum a essas narrativas é tomar o enigmático como uma característica racial, uma espécie de atributo metafísico do japonês. Mário de Andrade, como vimos, procura dar um tratamento histórico-social ao assunto, mas empregando categorias que ao mesmo tempo "naturalizam" a questão, transportam-na para o reino da natureza humana e das espécies em que se divide, entre elas a do "tigre japonês". Não sem lógica, indaga se "mesmo o japonês" é passível de aculturar-se. Já Oswald de Andrade, que trabalha (n)um cenário histórico por opção, esbarra a todo momento no estereótipo, nos clichês que cristalizam as

27 Cf. ANTÔNIO, João. Fujie. In: Malagueta, Perus e Bacanaço. Rio de Janeiro: Civilização Brasileira, 1963, p. 27-33. Registro semelhante é feito por Oswald de Andrade em Um homem sem profissão: sob as ordens de mamãe (Memórias: 189o1919). Rio de Janeiro: Civilização Brasileira, 1974, p. 138. Para o brasileiro, a mulher de origem nipônica parece ser sempre a enigmática, a exótica, de uma sensibilidade que se esconde e se manifesta obscuramente, explosivamente, como ocorre com Toiô, a criada de Deisi, com cuja imagem Oswald encerra essa obra. 
imagens do japonês em torno das ideias de dissimulação, isolamento (ou enquistamento), indiferença, invasão, ocupação ${ }^{28}$.

Aos escritores que abordaram o tema não parece ter ocorrido que esses traços pudessem ser produto e manifestação da dinâmica social, da dialética por vezes traumática que preside à convivência entre brasileiros, de um lado, e japoneses e seus descendentes, de outro. Não é difícil produzir ou fabricar o dissimulado, o misterioso e o reservado a partir de qualquer etnia: basta, desde os primeiros contatos, separá-la, por atos mentais e/ou pelo comportamento social. Por outras palavras, o ônus da dissimulação cabe tanto ao próprio dissimulado quanto àquele que, menosprezando sua cultura, debochando de seus traços físicos, o obriga a escolher entre ocultar - por vergonha, orgulho ou defesa - aquelas características que provocam no outro manifestações de desagrado, desdém ou troça, ou isolar-se (cultural e/ou fisicamente).

Levando isso em conta, é curioso que somente aos japoneses - ou sobretudo a eles - seja atribuída a prática da dissimulação, quando esta pode ser adivinhada ou flagrada em muitos outros grupos e atores da cena social brasileira. E nesse caso trata-se de lembrar não apenas a dissimulação dos contingentes sociais e étnicos que, em algum momento da história, sofreram a discriminação, mas também a dos próprios brasileiros. A malandragem - algo que certos autores consideram traço típico e distintivo do nacional - é, essencialmente, a arte da dissimulação ${ }^{29}$.

Trilhando o caminho do enigmático, a imagem se faz, ao mesmo tempo, contraditória, ambivalente: os japoneses são raça inferior - os

28 O narrador de Marco zero dá voz e guarida a praticamente toda a ideologia antinipônica sustentada e propagada, no período de concepção e composição do romance (grande parte da década de 1930 e início da década de 1940), por intelectuais como Vivaldo Coaracy (autor de O perigo japonês), Félix Pacheco, Arthur Neiva, Antônio Xavier de Oliveira, Miguel Couto, Francisco José de Oliveira Vianna, que alertaram contra o perigo de os imigrantes japoneses constituírem "quistos raciais" no Brasil, por conta de serem "inassimiláveis". Os argumentos então empregados - alguns inspirados nas ideias de Gobineau, tomadas como científicas, outros misturando manifestações de antiniponismo com declarações de seus autores protestando que não seriam racistas - são expostos, contextualizados e discutidos por NUCCI, Priscila. Os intelectuais diante do racismo antinipônico no Brasil: textos e silêncios. Dissertação de Mestrado em História, Instituto de Filosofia e Ciências Humanas, Unicamp, Campinas, 2ooo, 1566 .

29 "Minto por disciplina social e para não casar novamente na polícia”, diz Serafim Ponte Grande, o personagem-título do romance de Oswald de Andrade (Rio de Janeiro: Civilização Brasileira, 1980, p. 171) que Antonio Candido tem na conta de uma das "expressões máximas" da comicidade popularesca que "foge às esferas sancionadas da norma burguesa e vai encontrar a irreverência e a amoralidade de certas expressões populares" (cf. CANDIDO, Antonio. Dialética da malandragem. In: _. . O discurso e a cidade. São Paulo: Duas Cidades, 1993, p. 53). 
"amarelos" -, mas é de se temer que invadam e ocupem todo o Brasil e o mundo ${ }^{30}$; são dissimulados, mas não há dúvida de que seu verdadeiro papel é o de espiões e invasores (no mínimo, portanto, trata-se de uma dissimulação muito mal desempenhada...).

Mais uma vez, é preciso perguntar se essa imagem representa o imigrante japonês em sua viva realidade ou se não reflete um determinado modo de ver, se não é a projeção de uma imaginação algo paranoica. Em todo o caso, há que considerar, na gênese da imagem, a ambivalência do próprio brasileiro - ambivalência de quem convida e rejeita, de quem recebe e não acolhe. Convidados a sair de seu país, para engrossar a mão de obra das fazendas de café, os nipônicos acabaram sendo vistos como espiões-invasores; considerados diferentes, exóticos, suas diferenças não foram entretanto aceitas nem assimiladas ${ }^{31}$.

Finalmente, se há alguma coisa que o enigmático traduz de forma direta, é o desconhecimento, e nesse caso a aura enigmática que envolve a imagem do imigrante japonês pode ser vista como resultado de uma falta de vontade - ou mesmo de uma má vontade - de conhecer o japonês. Recebido com reservas e prevenção, quando não com uma maldisfarçada hostilidade que usou e abusou do escárnio para menosprezar e inferiorizar, o imigrante nipônico cultivou, desde então, atitudes pautadas pela introspecção, pela timidez, pelo caráter sisudo, "fechado". Reagiriam de

3o A suposição de que os japoneses não seriam inferiores, mas o contrário, também aparece no debate sobre a imigração nipônica no Brasil, mas de modo a reforçar a tese de sua exclusão. Apoiando-se em pesquisa feita pelos americanos Porteus e Babcock sobre os japoneses no Havaí, em 1926 (Temperament and Race), Oliveira Vianna afirma que os nipônicos devem ser excluídos precisamente por não serem inferiores: "Para nós o problema da assimilação do immigrante japonez é infinitamente mais difficil de resolver do que o dos immigrantes das outras raças aqui affluentes - e isto, não pela sua inferioridade, que fica patente não existir, mas pela sua incapacidade de se deixar absorver pela massa nacional. Qualidade que elle revela de modo quasi agressivo no Hawai, segundo os dois autores citados, e que, penso, há de se revelar em qualquer parte onde se fixe" (cf. VIANNA, Oliveira. Raça e assimilação. São Paulo: Cia. Ed. Nacional, 1934, p. 209).

31 Os primeiros imigrantes japoneses viveram e trabalharam no Brasil sob condições de semiescravidão, como revelam os vários tipos de relatos, inclusive o cinematográfico (cf. o filme Gaijin, de 1980, dirigido por Tizuka Yamazaki). O espectro da escravidão interpõe-se nas relações entre brasileiros e os indivíduos de origem nipônica, às vezes de forma crua e ofensiva (por exemplo, no dístico "japonês garantido/come tomate e peida fedido", que, aludindo às baixas funções fisiológicas, aproxima o japonês do negro que, "quando não faz na entrada, faz na saída"), outras de um modo ironicamente simpático e carinhoso: no já citado conto "Fujie", de João Antônio, o personagem narrador enlaça a personagem-título, ao final da narrativa, dizendo-lhe "Nega, benzinho"; Fujie ralha com ele - "Eu não sou negra" -, ao que o outro replica - "É só carinho que eu estou fazendo". Cf. ANTÔNIO, João, op. cit., p. 33. 
maneira diferente outros grupos étnicos se confrontados com o mesmo tipo de recepção? Perguntando de outra forma: não teria sido maior, mais rápida e mais intensa a integração dos imigrantes japoneses à sociedade brasileira se eles, desde o começo, tivessem sido tratados com espírito efetivamente aberto às diferenças étnico-culturais, verdadeiramente disposto a acolher e respeitar a diversidade, isento da pretensão de nivelar, rebaixar e uniformizar? 